\title{
Micro-interferometry of Insect Polyploid Nuclei
}

\author{
Maria Luiza S. Mello \\ Departamento de Genética da Faculdade de Medicina de Ribeirão Prêto. S. P., Brazil
}

Received September 2, 1970

\section{Introduction}

Interference microscopy has enabled investigators to determine the weight of unstained and even living cells and cellular components by precise optical means and has also provided a direct image of structural details with excellent and controllable contrast and high resolution (Mellors 1957). By interference microscopy measurements of dry mass of genetic material in sperm nuclei of the mouse, the rat and the guinea pig and of the different stages of grasshopper spermatogenesis have been reported (Mellors and Hlinka 1955, Watkins 1961).

Detection of polyploid nuclei in quantitative cytological analysis has used the number of chromosomes and, when this cannot be established, estimates of the nuclear DNA from cytophotometry and the nucleus size from caryometry. Microinterferometry procedures for determination of dry mass in polyploid somatic nuclei had been only used in the study of neoplasic cells in mouse tumours (Mellors et al. 1955, Mellors 1957) and of isolated diploid and tetraploid nuclei of adult rat liver (Bibbiani et al. 1969) and were considered of high precision, when comparisons were made with cytophotometric data for DNA.

Development of polyploidy in silk glands and Malpighian tubes of insects has been demonstrated in terms of DNA content per nucleus and nuclear size: In Hymenoptera the larval Malpighian tubes of Melipona quadrifasciata have polyploid nuclei during the post-embryonic development; DNA replications stop in the 3rd instar, while the nuclear volumes enlarge until the 4th instar (Mello and Takahashi 1969). DNA contents and nuclear volumes in the silk glands of the same bee increase until the 4th larval instar, but the increase in nuclear volume is greater than that in DNA content (Mello et al. 1970). The Malpighian tubes of Melipona quinquefasciata, a stingless bee which has germinative polyploid cells, show the same DNA content per nucleus as those of Melipona quadrifasciata (Mello and Silveira 1970).

In the present work some phenomena of somatic polyploidy in bees are investigated by micro-interferometric procedures. The dry masses of the nuclei are determined, and comparisons are made with reported karyometric and cytophotometric data, mainly in cases in which increases in nuclear volumes are not in accordance with DNA increases.

1 Present address: Setor de Citopatologia, Departamento de Histologia, Instituto de Biologia, Universidade Estadual de Campinas, S. P., Brazil: 


\section{Material and methods}

Worker stingless bees of Melipona quadrifasciata anthidioides Lep. and Melipona quinquefasciata Lep. were used.

The Malpighian tubes of Melipona quadrifasciata were studied in the five larval instars and prepupa, and the silk glands in the 3rd and 5th larval instars. The nuclei of the distal and proximal portions of the silk glands in the 3rd instar were investigated, since evidence of differential nuclear activity of parts of this organ has been reported (Mello et al. 1970). The Malpighian tubes and silk glands of Melipona quinquefasciata were studied in the last larval instar and compared with those of Melipona quadrifasciata.

The organs were dissected in $0.75 \%$ saline solution and left for 3-5 minutes in distilled water, which ruptures cells and liberates nuclei and this was observed with the interference microscope. The nuclei were then immersed in Carlson's medium (Shaw 1956) in order to have their dry masses determined after 20 minutes.

Observations were made with a Zeiss photomicroscope equipped for polarization and interference (Pol-Interferencial) with monochromatic light $(\lambda=546 \mathrm{~nm})$ for an U.V. source.

Dry mass in grams of material was given by the formula

$$
m=\Phi_{m} \frac{A}{\chi}+(\mu m-\mu w) t \frac{A}{\chi}, \text { where }
$$

$\Phi_{m}$ is the optical path difference measured relative to the medium of refractive index $\mu m ; A$, the area of the nucleus $\left(\mathrm{cm}^{2}\right) ; \mu_{m}=1.336$ (refractive index of Carlson's medium); $\mu_{w}=1.333$ (refractive index of distilled water); $t$, the nucleus thickness, and $\chi(=100 \alpha)=0.18$ (Davies et al. 1954).

Measurement of the optical path difference was computed with the Senarmont's method, in which compensation is determined by a rotatory analyser. The nuclear diameter was measured with a delicate rotatory vernier scale inserted in a special eye-piece (Leitz).

Errors in the dry mass determinations due to the assumption of an average $\alpha$ value of 0.0018 do not exceed $\pm 10 \%$ in cells containing mainly solutions or gels of proteins, lipoproteins, and nucleic acids (Davies et al. 1954). This error could arise only if the structure consisted entirely of only one of these substances. It would be less in a mixture of these substances as in the nuclei. Since the main component of nuclei is often protein, 0.0018 is an accurate value for $\alpha$ (Hale 1958).

Nucleic acids and histones were extracted from nuclei of silk glands and Malpighian tubes in the last larval instar of Melipona quadrifasciata for calculation of their part in the dry mass of the nuclei. Nucleic acids were extracted in a $5 \%$ aqueous solution of TCA for 2 hours at $90^{\circ} \mathrm{C}$ (Davies et al. 1957). The completeness of extraction with TCA was checked by Einarson's chromalum-gallocyanin staining (1951). Digestion of histones was investigated with a $0.5 \%$ trypsin solution in $0.75 \%$ saline solution for 12 hours at $36^{\circ} \mathrm{C}$ (modified from Davies et al. 1954). A collagen bundle was used as a control for trypsin action.

All drv mass calculations were performed on an IBM-360 computer. 
Original data were placed on a scale of values in geometric progression since they have a long-normal distribution and this kind of scale avoids the search for logarithms (Ferreira et al. 1967).

\section{Results}

The nuclei of the Malpighian tubes of Melipona quadrifasciata in the larval instars and prepupa had the dry masses plotted as frequency histograms (Fig. 1) and these data may be compared with Mello and Takahashi's (1969) karyometric and cytophotometric values on somatic polyploidy (Table 1). The last doubling of nuclear volume and dry mass occurs in the 4th larval instar but is not accompanied by an increase in DNA content.

Table 1. Summary of data of the nuclei from the larval Malpighian tubes of Melipona quadrifasciata

\begin{tabular}{|c|c|c|c|c|c|c|}
\hline Stages & 1st instar & 2nd instar & 3rd instar & 4th instar & 5 th instar & Prepupa \\
\hline $\begin{array}{l}\text { Nuclear dry } \\
\text { masses } \\
(\mathrm{D} \pm \mathrm{Sd}) \\
10^{-11} \mathrm{~g}\end{array}$ & $4.18 \pm 2.76$ & $12.62 \pm 6.16$ & $35.34 \pm 12.10$ & $70.75 \pm 19.69$ & $77.90 \pm 10.17$ & $78.60 \pm 21.28$ \\
\hline $\begin{array}{l}\text { Nuclear dry } \\
\text { masses after } \\
\text { hot TCA } \\
\text { (D } \pm \text { Sd) } \\
10^{-11} \mathrm{~g}\end{array}$ & - & - & - & - & $44.76 \pm 16.02$ & - \\
\hline $\begin{array}{l}\text { Per cent } \\
\text { loss after } \\
\text { hot TCA }\end{array}$ & - & - & $\longrightarrow$ & - & 42.59 & - \\
\hline $\begin{array}{l}\text { Nuclear dry } \\
\text { masses after } \\
\text { trypsin } \\
(\mathrm{D} \pm \mathrm{Sd}) \\
10^{-11} \mathrm{~g}\end{array}$ & - & 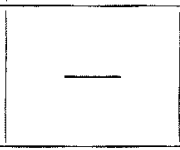 & - & - & $67.25 \pm 10.26$ & - \\
\hline $\begin{array}{l}\text { Per cent } \\
\text { loss after } \\
\text { trypsin }\end{array}$ & - & - & - & - & 13.74 & - \\
\hline $\begin{array}{l}\text { Doublings } \\
\text { in nuclear } \\
\text { dry masses }\end{array}$ & $\begin{array}{l}y, 2 y \\
4 y, 8 y\end{array}$ & $\begin{array}{l}4 y, 8 y \\
16 y\end{array}$ & $16 y, 32 y$ & $64 y$ & $64 y$ & $64 y$ \\
\hline $\begin{array}{l}\text { Doublings } \\
\text { in nuclear } \\
\text { volumes } \\
\text { according to } \\
\text { Mello and } \\
\text { Takahashi } \\
\text { (1969) }\end{array}$ & $\begin{array}{l}4 x, 8 x \\
16 x, 32 x\end{array}$ & $16 x, 32 x$ & $16 x, 32 x$ & $\begin{array}{l}16 x, 32 x \\
64 x\end{array}$ & $\begin{array}{l}16 x, 32 x \\
64 x\end{array}$ & $\begin{array}{l}16 x, 32 x \\
64 x\end{array}$ \\
\hline $\begin{array}{l}\text { DNA replica- } \\
\text { tions } \\
\text { according to } \\
\text { Mello and } \\
\text { Takahashi } \\
(1969)\end{array}$ & $\begin{array}{l}4 n, 8 n, \\
16 n\end{array}$ & $16 n, 32 n$ & $16 n, 32 n$ & $16 n, 32 n$ & $16 n, 32 n$ & $16 n, 32 n$ \\
\hline
\end{tabular}

Higher values of dry masses are seen in the distal portion of the silk glands of Melipona quadrifasciata in the 3rd larval instar (Fig. 2) and this is in accordance with the two main ploidy degrees in terms of DNA content ( $8 n$ and $16 n$ ) and nuclear volumes assumed by Mello et al. (1970). In the 5th larval instar most of the values are placed in an interval range higher than that found in the distal 3rd instar (Fig. 3) 


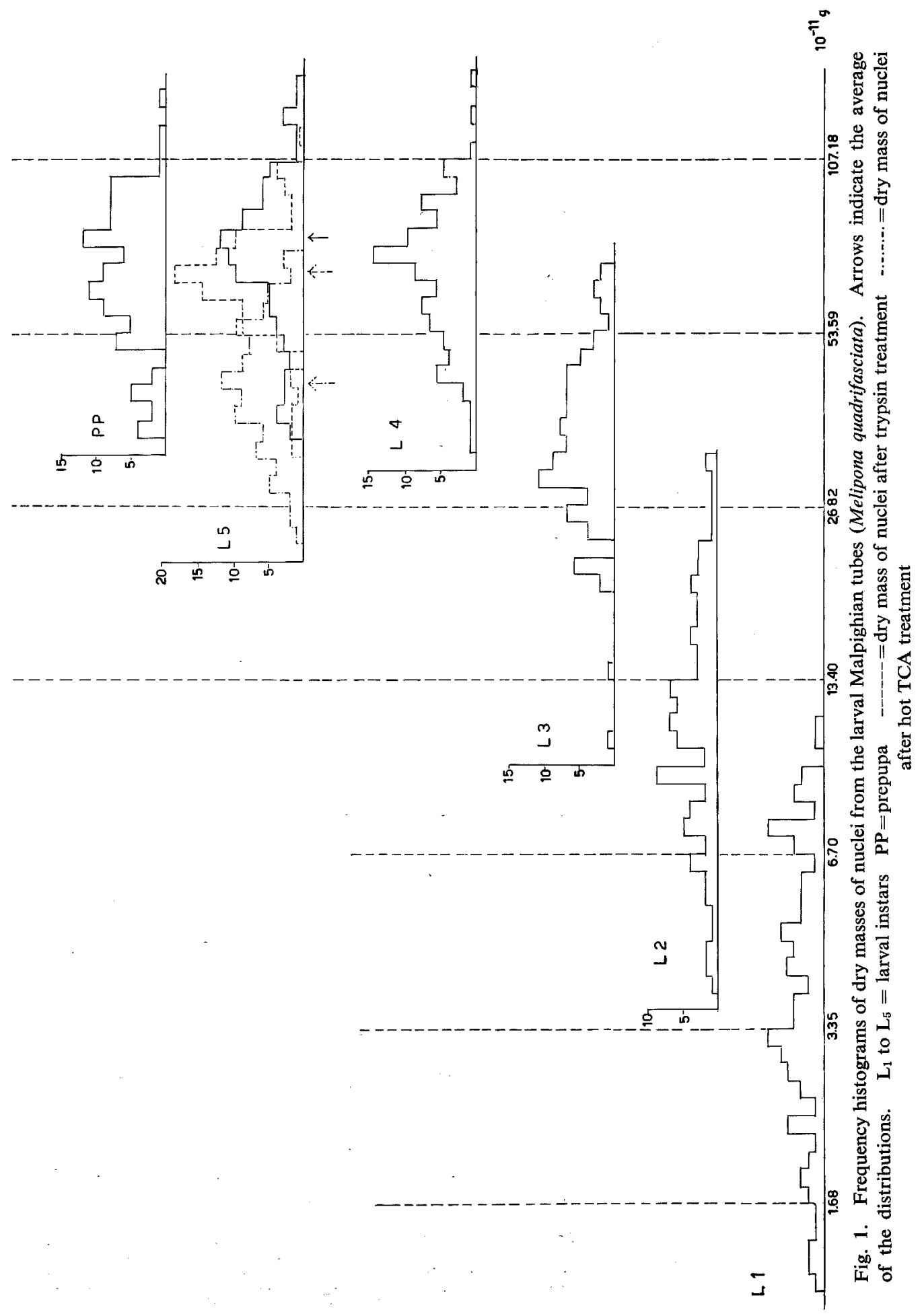




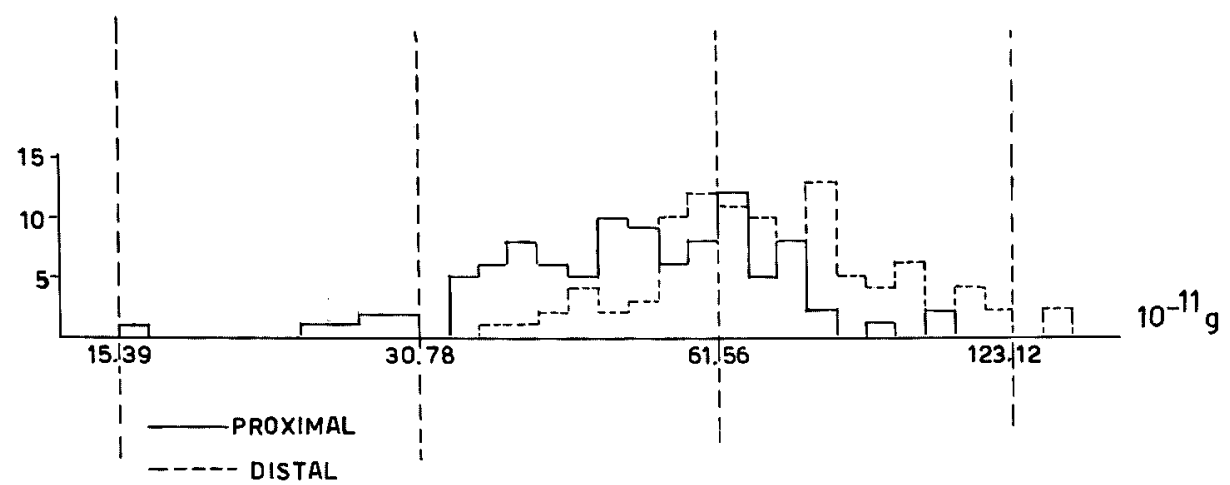

Fig. 2. Frequency histograms of dry masses of proximal and distal nuclei from the silk glands in the 3rd larval instar (Melipona quadrifasciata).

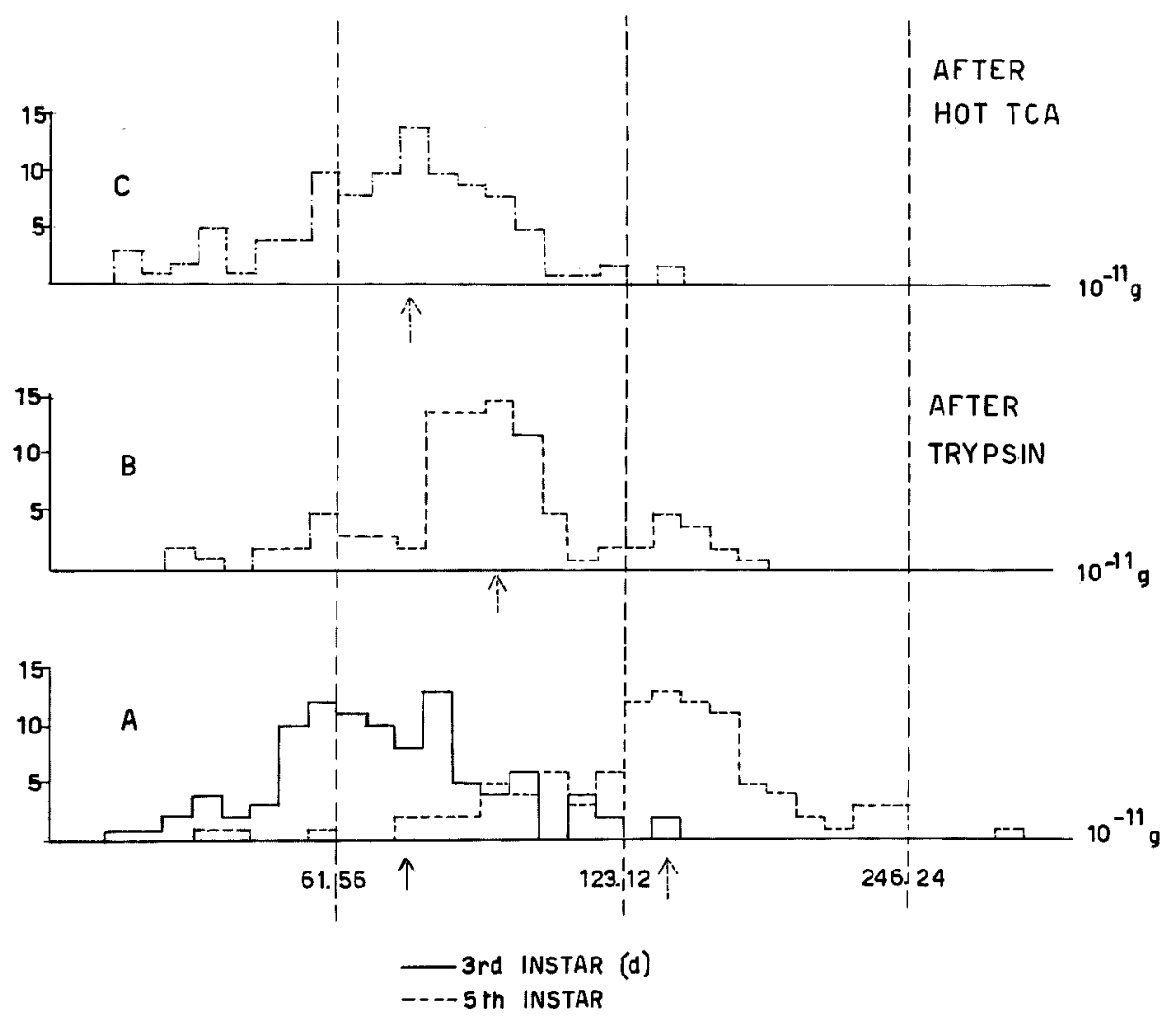

Fig. 3. Frequency histograms of dry masses of distal nuclei from the silk glands in the 3rd and 5 th larval instars (A) and of the 5th instar nuclei after trypsin (B) and hot TCA (C) treatments (Melipona quadrifasciata). 


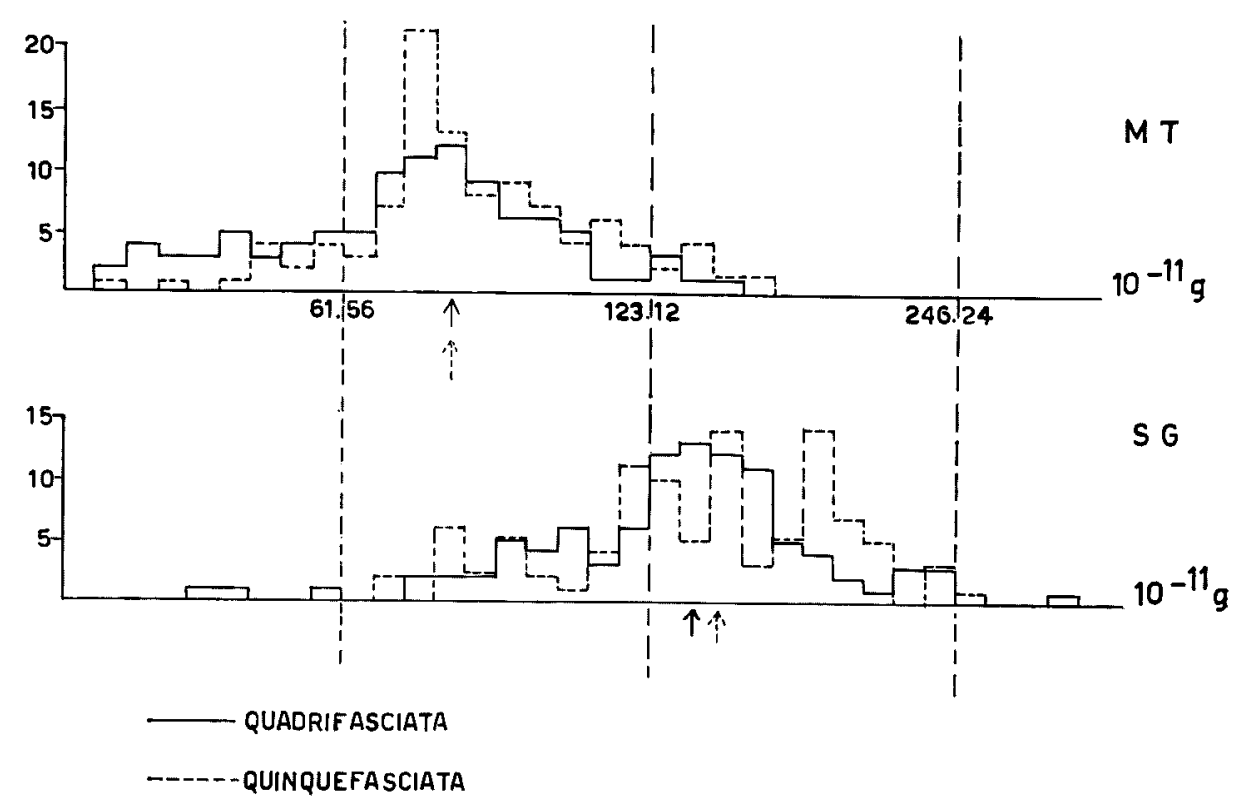

Fig. 4. Frequency histograms of dry masses of the nuclei from Malpighian tubes (MT) and silk glands (SG) in the 5th larval instar (Melipona quadrifasciata and M. quinquefasciata).

Table 2. Summary of data of the nuclei from the silk glands of Melipona quadrifasciata

\begin{tabular}{|c|c|c|c|}
\hline Larval instars & \multicolumn{2}{|c|}{$3 \mathrm{rd}$} & 5 th \\
\hline $\begin{array}{l}\text { Portions of the } \\
\text { silk glands }\end{array}$ & Proximal & Distal & Distal \\
\hline $\begin{array}{l}\text { Nuclear dry masses } \\
(\mathrm{D} \pm \mathrm{Sd}) \mathbf{1 0}^{-11} \mathrm{~g}\end{array}$ & $52.80 \pm 16.04$ & $71.71 \pm 19.19$ & $137.90 \pm 32.51$ \\
\hline $\begin{array}{l}\text { Dry mass after hot TCA } \\
(\mathrm{D} \pm \mathrm{Sd})\left(10^{-11} \mathrm{~g}\right)\end{array}$ & - & - & $72.47 \pm 18.18$ \\
\hline $\begin{array}{l}\text { Per cent loss after } \\
\text { hot TCA }\end{array}$ & - & - & 47.45 \\
\hline $\begin{array}{l}\text { Dry mass after trypsin } \\
(D \pm S d)\left(10^{-11} \mathrm{~g}\right)\end{array}$ & - & - & $89.76 \pm 14.09$ \\
\hline Per cent loss after trypsin & - & - & 34.92 \\
\hline $\begin{array}{l}\text { Doublings in nuclear dry } \\
\text { masses }\end{array}$ & $4 y, 8 y^{1}$ & $8 y, 16 y$ & $16 y, \underline{32 y}$ \\
\hline $\begin{array}{l}\text { Doublings in nuclear } \\
\text { volumes according to } \\
\text { Mello et al. (1970) }\end{array}$ & $4 x, 8 x$ & $8 x, \underline{16 x}$ & $16 x, 32 x, 64 x$ \\
\hline $\begin{array}{l}\text { DNA replications } \\
\text { according to } \\
\text { Mello et al. }(1970)\end{array}$ & $4 n, 8 n$ & $8 \mathrm{n}, 16 \mathrm{n}$ & $\underline{32 \mathrm{n}}, 64 \mathrm{n}$ \\
\hline
\end{tabular}

${ }_{1}$ Underlined values correspond to the most populated interval. 
and correspond to $32 \mathrm{n}$ interval according to cytophotometric data for DNA reported by Mello et al. (1970) (Table 2).

The dry mass of the nuclei from Malpighian tubes and silk glands of Melipona quinquefasciata are slightly larger than those of Melipona quadrifasciata (Fig. 4). The values of arithmetic mean with standard deviation for these organs are:

Malpighian tubes: $\quad 80.23 \pm 25.48 \times 10^{-11} \mathrm{~g}$ ( $M$. quinquefasciata) $77.90 \pm 20.17 \times 10^{-11} \mathrm{~g}$ (M. quadrifasciata)

Silk glands: $\quad 144.40 \pm 42.45 \times 10^{-11} \mathrm{~g}$ (M. quinquefasciata) $137.90 \pm 29.51 \times 10^{-11} \mathrm{~g}$ (M. quadrifasciata)

The dry masses of the nuclei from Malpighian tubes and silk glands of Melipona quadrifasciata after hot TCA and trypsin treatments were determined in the 5 th instar. Since the main mode of the distributions before and after treatments is placed within the same distribution range as the arithmetic mean values, the percentage of losses was calculated by using the arithmetic means of this instar (Tables 1 and 2).

\section{Discussion}

Increases in DNA content and nuclear volumes in the Malpighian tubes of Melipona quadrifasciata have been reported to be proportional each other until the 3rd larval instar, when DNA replications stop but the nuclear volumes duplicate once more (Mello and Takahashi 1969). This last enlargement of nucleus size is accompanied by an increase in the dry mass of the nucleus, and from the duplication values one can assume that the dry mass is in accordance with data from nuclear volume/DNA ratio (Table 1).

Such variations in nucleus enlargement have been attributed to non-histonic proteins (Mellors 1957, Alfert 1959). According to Schreiber et al. (1966) an extra doubling of nuclear volume would be related to a double amount of acidic proteins which would act as de-repressors of genetic loci, by displacing histones and allowing RNA transcription. Since histones are indeed inhibitors of gene function, the displacement of these inhibitors by non-histonic proteins (or RNA) would influence gene activity (Markert, 1965, in Schreiber et al. 1966). In Chironomus salivary glands acidic proteins have also been reported in the transport of RNA from chromosome to cytoplasm (Stevens and Swift 1966, Berendes 1968). There is a trypsin-resistant, DNAse sensitive core inclosed in a trypsin-sensitive sheath in honey-bee chromatin fibers (DuPraw 1965). Presumably histones constitute a significant part of the sheath proteins, since they are known to be associated quantitatively with chromosomal DNA and to be synthesized when DNA is synthesized. The amount of histone, however, is lesser than that expected on the basis of total mass of the sheath. The bulk of the sheath protein is thought to be acidic, which is supported by the fact that isolated metaphase chromosomes are stabilized in acid solution (Chorazy et al. 1963, DuPraw 1965). Therefore, one can assume that most of the remaining nuclear dry mass of nuclei from Melipona quadrifasciata Malpighian tubes is due to acidic proteins.

Values of dry masses duplications in the nuclei of Melipona quadrifasciata 
silk glands are in accordance with the endopolyploid gradient regarding distal and proximal portions of the organ (3rd instar). Since the main values of nuclear volume duplications in the 5th instar $(64 x)$ are larger than most of DNA contents (32n) and dry masses (32y), it is suggested that there is a high hydration level of the nuclear material of the silk glands in this stage. Values of dry masses of the silk glands in the 5th instar are twice those of the Malpighian tubes in the same instar (Fig. 3).

Material extracted with hot TCA or trypsin allow us to assume that there are $35.31 \times 10^{-11} \mathrm{~g}$ of nucleic acids in the nuclei of the Malpighian tubes of Melipona quadrifasciata in the last larval instar $(42.59 \%$ to total dry mass of the nuclei) and $10.75 \times 10^{-11} \mathrm{~g}$ of histones $(13.74 \%)$. In the silk glands of the last larval instar of the same bee there are $65.43 \times 10^{-11} \mathrm{~g}$ of nucleic acids (which account for $47.45 \%$ to total dry mass) and $48.14 \times 10^{-11} \mathrm{~g}(34.92 \%)$.

The results with respect to nucleic acids (DNA and RNA) are not unexpected since the ratio of DNA only to total dry mass determined by U.V. and interference microscopy has been shown to be $40 \%$ in living ram sperm heads (Davies et al. 1954).

The trypsin action may have not been complete, but since the time of treatment was the same for silk glands and Malpighian tubes, differences in the results may be analysed and considered of interest. Histones are in a higher percentage in the silk glands than in the Malpighian tubes perhaps due to a greater specialization for protein synthesis in the silk glands, while Malpighian tubes are specialized for excretion of lipid globules (Mello and Bozzo 1969). Therefore, in the silk glands whose genes are more directly activated, providing the protein synthesis, a large repression of other genes not concerned with this event would occur. Then histones in the silk glands are 4 times those of the Malpighian tubes. Histones act as inhibitors of RNA synthesis in the nuclei (Allfrey 1963) and are associated with those genes which are permanently inactive, since many genes must remain repressed throughout the whole life of a cell (Butler 1966).

The dry mass values in the Malpighian tubes of Melipona quinquefasciata are slightly higher than those of Melipona quadrifasciata, while the nuclear volumes are approximately the same in both species (Mello and Silveria 1970). Then one can assume that the differences in nuclear volumes are probably concerned with different degrees of hydration in the nuclei besides increase in acidic proteins. DNA cytophotometric data suggest that the nuclei in the larval Malpighian tubes of $M$. quinquefasciata undergo three DNA replications while in $M$. quadrifasciata they undergo four DNA replications (Mello and Silveira 1970). Micro-interferometric data support this interpretation and show that the same pattern occurs in the silk glands.

\section{Summary}

The dry masses of isolated polyploid nuclei from somatic tissues of bees may be established by micro-interferometric procedures and are often in accordance with cytophotometric values for DNA. Increases over those expected from 
polyploidy in nuclear volumes and in nuclear dry masses of Melipona quadrifasciata Malpighian tubes may be due to non-histonic proteins, but in Melipona quinquefasciata such increases are also probably concerned with hydrating factors. The histone content removed by trypsin in the last larval instar of Melipona quadrifasciata is higher in the silk glands than in the Malpighian tubes, perhaps due to a large repression of genes not concerned with protein synthesis in the silk glands.

\section{Acknowledgements}

The author is indebted to Prof. Benedicto de Campos Vidal for encouragement, valuable discussions and criticism, to Prof. Lucien Lison for criticism and colaboration in programing the data for computation and to Prof. Charles D. Michener for helping with the manuscript. The supports of Fundação de Amparo à Pesquisa do Estado de São Paulo, Rockefeller Foundation and Conselho Nacional de Pesquisas are gratefully acknowledged.

\section{References}

Alfert, M. 1959. Variations in cytochemical properties of cell nuclei. Exp. Cell Res., Suppl. 6: 227-235.

Allfrey, V. G. 1963. The functional biochemistry of cell structures. In Proc. Vth Intern. Congr. Biochem. Oxford: Pergamon Press.

Berendes, H. D. 1968. Factors involved in the expression of gene activity in polytene chromosomes. 24: 418-437.

Bibbiani, C., Tongiani, R. and Viola-Magni, M. P. 1969. I. Quantitative determination of the amount of DNA per nucleus by interference microscopy. Cell Biol. 42: 444-451.

Butler, J. A. V. 1966. Complexity and specificity of histones. In Histones (Ciba Foundation Study Group N. 24). Boston: Little Brown \& Co.

Chorazy, N., Bendich, A., Borenfreund, E. and Hutchison, D. J. 1963. Studies on the isolation of metaphase chromosomes. J. Cell Biol. 19: 59-69.

Davies, H. G., Deeley, E. M. and Denby, E. F. 1957. Attempts at measurement of lipid, nucleic acid and protein content of cell nuclei by microscope-interferometry. Exp. Cell Res., Suppl. 4: 136-149.

-, Wilkins, M. H. F., Chayen, J. and LaCour, L. F. 1954. The use of the interference microscope to determine dry mass in living cells and as a quantitative cytochemical method. Quart. J. Micr. Sci. 95: 271-304.

DuPraw, E. J. 1965. Macromolecular organization of nuclei and chromosomes: a folded fibre model based on whole-mount electron microscopy. Nature 206: 338-343.

Einarson, L. 1951. On the theory of gallocyanin-chromalum staining and its application for quantitative estimation of basophilia. A selective staining of exquisite progressivity. Acta path. microbiol. Scand. 28: 82-102.

Ferreira, A. L., Lison, L. and Valeri, V. 1967. Caryometric study of spermatogenesis in the rat. Z. Zellforschg. 76: 31-55.

Hale, A. J. 1958. The Interference Microscope in Biological Research. London: E. \& S. Livingstone Ltd.

Mello, M. L.S. and Takahashi, C.S. 1969. The post-embryonic changes in Melipona quadrifasciata anthidioides Lep. (Hym., Apoidea) V. Polyploidy in the larval Malpighian tubules. Cytologia 34: 369-374.

- and Bozzo, L. 1969. Histochemistry, refractometry and fine structure of excretory globules 
of larval Malpighian tubes of Melipona quadrifasciata (Hym., Apoidea). Protoplasma 68: $241-251$.

-, Takahashi, C. S. and Gagliardi, A. R. T. 1970. Polyploidy pattern in the larval silk glands of Melipona quadrifasciata (Hym., Apoidea). Insectes Sociaux 17: 295-302.

- and Silveira, Z. V. 1970. Somatic polyploidy in the larval Malpighian tubes of Melipona quinquefasciata Lep. (Hym., Apoidea). Nucleus 13: 59-61.

Mellors, R. C. 1957. Cancer Biology, Biochemistry and Pathology. In Analytical Pathology. New York: McGraw-Hill Book Co., Inc.

- and Hlinka, J. 1955. Quantitative cytology and cytopathology IV. Interferometric measurement of the anhydrous organic mass (dry weight) of genetic material in sperm nuclei of mouse, the rat and the guinea pig. Exp. Cell Res. 9: 128-134.

-, Ortega, L. G., Stoholski, A. and Hlinka, J. 1955. Optical measurements of the quantity of nucleoprotein material in chromosomes of cancer cells of the mouse. Proc. Am. Assoc. Cancer Res. 2: 33-39.

Schreiber, G., Melluci, N. B., Gerken, S. E., Sant'Ana, Y. X., Fallieri, L. A., e Amorim, F. O. 1966. Pesquisas de citologia quantitativa XIX. DNA e volume nuclear nos tecidos somaticos dos vertebrados. Mem. Inst. Butantan 33: 135-150.

Shaw, E. I. 1956. A glutamic acid-glycine medium for porolonged maintenance of high mitotic activity in grasshopper neuroblasts. Exp. Cell Res. 11: 580-586.

Stevens, B. J. and Swift, H. 1966. RNA transport from nucleus to cytoplasm in Chironomus salivary glands. J. Cell Biol. 31 : 55-71.

Watkins, M. 1961. Interferometric measurements of the chromosomal mass in a grasshopper. Exp. Cell Res. 23: 595-602. 